\title{
Mark Wilson Jones: Origins of Classical Architecture: Temples, Orders and Gifts to the Gods in Ancient Greece
}

\author{
Yale University Press, 2014
}

\section{Filippo Fantini ${ }^{1}$}

\begin{abstract}
The recent work by Mark Wilson Jones addresses a fundamental topic: the explanation of the reasons of classical architecture, its legacy, its everlasting success in Western architecture, the reflections of its archetypes in contemporary culture (and not only in architecture).
\end{abstract}

Keywords Classical architecture - Greek architecture - Temples · Archaeology $\cdot$ Symmetria $\cdot$ Eurythmia

As in other research fields, the study of the origins of a complex matter such as Architecture - the deep knowledge of the substratum upon which every further development is based-is in constant need of re-examination. Almost every thirty years a deep revision of the fundamentals of a discipline, that is, its general perception as intended by the public of specialists, as well as non-specialists, is required. The more we know about specific issues (individual buildings, ancient treatises, manuals, etc.), the more we must update our vision of a pluralistic multifaceted reality such as ancient Greek architecture. New cultural scenarios, new discoveries, a new lexicon, lead to the need to reconsider previous assumptions; therefore basic research fields can be considered as inexhaustible mines for fruitful research.

However some authors do not work exactly that way. Some reach such a deep understanding of the stratified concepts underlying a specific topic that with their work and authority they can get rid of outdated and unreliable convictions and

Filippo Fantini

filippo.fantini2@unibo.it

1 Dipartimento di Architettura, Alma Mater Studiorum Università di Bologna, Viale Risorgimento 2, Bologna, Italy 
unveil new perspectives of research in an academic matter that one would consider as already investigated in depth. An example of this phenomenon can be seen in Silvio Ferri's seminal analysis on Vitruvius (2002), which paved the way to the specifications of other scholars, such as Robert L. Scranton (1974), Pierre Gros (1997) and Antonio Corso (2012), who then arrived at a better and more accurate understanding of the Latin author's treatise. The recent work by Mark Wilson Jones (2014), Origins of Classical Architecture: Temples, Orders and Gifts to the Gods in Ancient Greece (Fig. 1), can be considered as belonging to the "family" of these seminal writings, but where they were more centred on Latin philology, that of Wilson Jones has a wider scope than a simply Vitruvian exegesis: the explanation of the reasons of classical architecture, its legacy, its everlasting success in Western architecture, the reflections of its archetypes in contemporary culture (and not only in architecture).

One of the more astonishing qualities of this book, in addition to his brilliant and accurate style, is the author's original approach to the narration of facts and theories concerning well-known topics in comparison to recently published works characterized by similar challenging aims. Wilson Jones, rather than offering an interpretative structure based on the traditional categories such as space and time, focuses his interpretation on the temple typology, seen as a general category containing, among others building types of Greek architecture, the theoretical key to explain the evolving process and success of long-standing archetypes of Western architecture (Introduction and Chapters 1 and 2). However, he goes far beyond traditional assumptions based on the hermeneutics of the only surviving treatise from antiquity (Vitruvius) and its dogmatic interpretation by Renaissance scholars.

Fig. 1 The cover of the origins of classical architecture

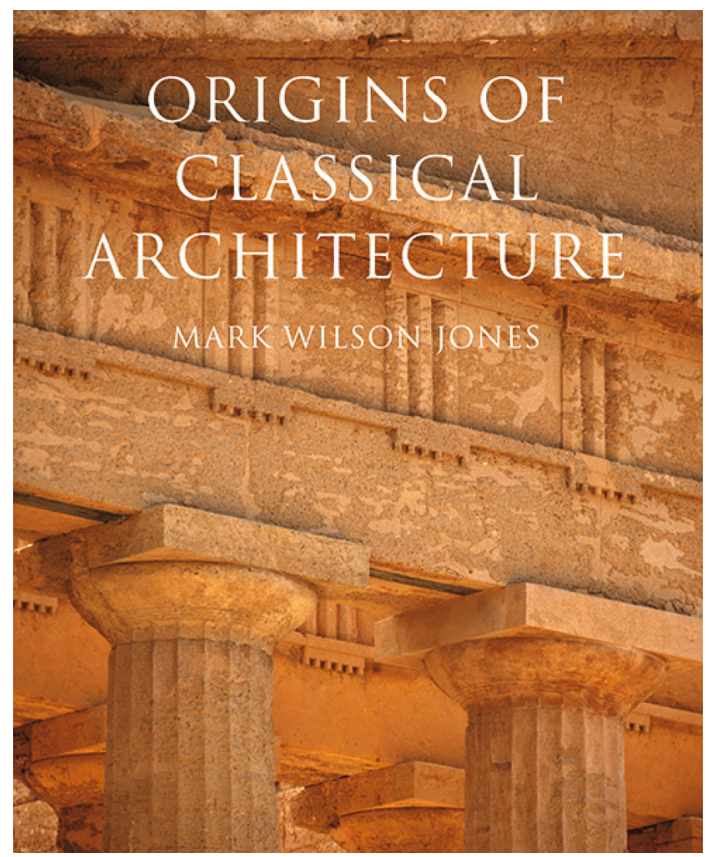


Here Wilson Jones is aided by his deep and wide-ranging knowledge of the most recent achievements coming from field of archaeology, supplying the reader with an extensive and updated bibliography, ranging gracefully among different research areas.

The evolution and the clarification of the genus is indeed the very core of the book, comprising Chapters 3-6, explaining with very accurately and with several examples the reciprocal influences of each type of peristasis, a temple feature Wilson Jones considers to be primarily a Greek invention, distinguishing it from previous examples of Egyptian colonnades. The other chapters address several types of elements forming part of the temple: symbolism; liturgy (the objects needed for rituals); gifts to the gods (Chapter 7); triglyphs and tripods (Chapter 8), crucible (Chapter 9). Every topic and issue, from the more general to the smaller details of the decorations, are perfectly illustrated without exception, by means of a vast and heterogeneous set of images. In particular, those belonging to the pensionnaire academic experience, stand out with their vivid watercolours testifying to the original aspect of the temple with its statues, its gifts and its urban or naturalistic environment (see, for instance, the depiction of the Sanctuary of Asklepios by Alphonse Defrasse, or that of the Temple of Zeus by Victor Laloux). Digital reconstructions and interpretations by means of 3D models are also graciously present, as well as an extensive selection of pictures which is a fundamental part of the book's charm: these practical visual examples take the readers through the comprehension of the core issues of classical architecture, namely the symbolism of structural elements and their relations at different scales. Graphic schemes, summary tables and a vast iconographic collection-not limited solely to architecture but to a wide ensemble of artefacts belonging to antiquity-when looked at all together, facilitate the comprehension of texts without sacrificing scientific accuracy. Wilson Jones puts emphasis on different topics concerning the hidden reasons of the evolution of Greek architecture. In particular he underlines the importance of competition among poleis (a central cultural feature, for example, Olympic games) as one of the main "engines" that drove Hellenic populations to give shape and codes to temple aesthetics in general, and to its constitutive elements and decorations in particular:

progress was fuelled by love of competition, a central characteristic of Hellenic culture that is manifest in sport and the performing arts, not forgetting state-level contests for prominent sculptural commissions and building projects (2014: p. 197).

In this sense, the "origins" are just one of the subjects of the book, since they are enunciated by Wilson Jones as starting points in order to explain why structural and functional elements have undergone such a sophisticated process - so unique- to make them "classical" for the history of architecture. The answers that the author lists are numerous.

The Greek design method is seen as a tool, improving over time in a way that was neither systematic nor linear, but nevertheless able to lead to a general semantical structure of the temple, as well as to specific proportions of the building's elements, moving from the initial eclectic character and contrasts to the coherence achieved 
with maturity. Variable requirements and constant improvement of visual impact admit only one exception: temples began as and remained houses for the Gods and the offerings given to them.

The process, from the geometric and mathematical point of view is explained in the fifth chapter concerning the Ionic genus, in which the author retraces the Vitruvian design process leading to the qualities of built architecture: mainly symmetria, eurythmia, and optics, an expedient enabling the achievement of a better and more proper perception of the temple.

The book ends with Chapter 10, "Questions Answered and Unanswered", in which the achievements by the author are systematically commented. The concluding chapter also provides a full set of still open questions mainly focused on Doric and Ionic styles (evolution in space and time, codification, fortune), which the author leaves to the reader.

\section{References}

Corso, Antonio. 2012. I disegni che corredavano il "De Architectura" nel contesto delle rappresentazioni antiche di temi architettonici. In Clini, Paolo (Ed.), Vitruvio e il disegno di architettura. Venezia: Marsilio/centro Studi Vitruviani: pp. 47-48.

Ferri, Silvio (ed.). 2002. Vitruvio. Architettura (Libri I-VII). Rome: Fratelli Palombi Editori, Rome.

Gros, Pierre (ed.). 1997. Vitruvio. De Architectura. Trans. and comm. Antonio Corso and Elisa Romano. Torino: Einaudi.

Scranton, Robert L. 1974. Vitruvius' Arts of Architecture. Hesperia 43 (4): 494-499.

Wilson Jones, Mark. 2014. Origins of Classical Architecture: Temples, Orders and Gifts to the Gods in Ancient Greece. New Haven/London: Yale University Press.

Filippo Fantini graduated with honors from the Polytechnic of Milan with a degree in museography in 2003. Starting from 2004 he collaborates regularly with the Department of Architecture-Design, History, Project of the University of Florence with which he participated in numerous surveying campaigns aimed at the documentation of sites from the particular historic and artistic interest such as: Villa Adriana (Tivoli), the Villa of Tiberius at Sperlonga (Latina), the walls of Massa Marittima (Grosseto), the Han Yang Ling Museum in Xian (Shaanxi, China) and the palace of Herod the Great at Masada (Israel). Professor of computer aided design at the Faculty of Industrial Design at the University of Florence in 2005. He won a PhD in the scientific field ICAR 17 in December 2005. From July 2009 to June 2011 had the scholarship "Santiago Grisolia" at the Instituto de Restauracion del Patrimonio (IRP) of the Polytechnic University of Valencia where he worked with a group of experts at a project funded by the European Commission, called "ATHENA" focused on enhancement and sustainable use of some of the most famous ancient theaters in the Mediterranean (Merida, Syracuse, Jarash, Caesarea, Carthage). Since September 2013 he has been a research professor at the Universita' degli Studi di Bolonga, Campus of Ravenna. Main topics of research activity: Classical Archeology, Ancient Greek and Roman Theatre Classical Architectural Decoration, Villa Adriana, 3D Modelling, 3D Laser scanning, Digital Photogrammetry, Reverse Modeling. 